OPEN ACCESS

Edited by:

Penglei Chen,

Institute of Chemistry (CAS), China

Reviewed by:

Sriram Kanvah,

Indian Institute of Technology

Gandhinagar, India

Jun Yin,

Central China Normal University, China

Ye Tian,

Nanjing University, China

${ }^{*}$ Correspondence:

Mathieu Surin

mathieu.surin@umons.ac.be

Sébastien Clément

sebastien.clement1@umontpellier.fr

Specialty section: This article was submitted to

Supramolecular Chemistry, a section of the journal

Frontiers in Chemistry

Received: 13 April 2019 Accepted: 26 June 2019

Published: 11 July 2019

Citation:

Kotras C, Fossépré M, Roger M, Gervais V, Richeter S, Gerbier P,

Ulrich $S$, Surin $M$ and Clément $S$ (2019) A Cationic Tetraphenylethene as a Light-Up Supramolecular Probe

for DNA G-Quadruplexes.

Front. Chem. 7:493

doi: 10.3389/fchem.2019.00493

\section{A Cationic Tetraphenylethene as a Light-Up Supramolecular Probe for DNA G-Quadruplexes}

\author{
Clément Kotras 1,2, Mathieu Fossépré ${ }^{2}$, Maxime Roger ${ }^{1}$, Virginie Gervais ${ }^{3}$, \\ Sébastien Richeter ${ }^{1}$, Philippe Gerbier ${ }^{1}$, Sébastien Ulrich ${ }^{4}$, Mathieu Surin ${ }^{2 *}$ and \\ Sébastien Clément ${ }^{1 *}$
}

${ }^{1}$ ICGM Institut Charles Gerhardt Montpellier, UMR 5253, CNRS, Université de Montpellier, ENSCM, Montpellier, France, ${ }^{2}$ Laboratory for Chemistry of Novel Materials, Center of Innovation and Research in Materials and Polymers, University of Mons-UMONS, Mons, Belgium, ${ }^{3}$ Institut de Pharmacologie et de Biologie Structurale, CNRS, IPBS, Université de Toulouse, Toulouse, France, ${ }^{4}$ Institut des Biomolécules Max Mousseron, IBMM, UMR 5247, CNRS, Université de Montpellier, ENSCM, Montpellier, France

Guanine-quadruplexes (G4s) are targets for anticancer therapeutics. In this context, human telomeric DNA (HT-DNA) that can fold into G4s sequences are of particular interest, and their stabilization with small molecules through a visualizable process has become a challenge. As a new type of ligand for HT-G4, we designed a tetraimidazolium tetraphenylethene (TPE-Im) as a water-soluble light-up G4 probe. We study its G4-binding properties with HT-DNA by UV-Visible absorption, circular dichroism and fluorescence spectroscopies, which provide insights into the interactions between TPE-Im and G4-DNA. Remarkably, TPE-Im shows a strong fluorescence enhancement and large shifts upon binding to G4, which is valuable for detecting G4s. The association constants for the TPE-Im/G4 complex were evaluated in different solution conditions via isothermal titration calorimetry (ITC), and its binding modes were explored by molecular modeling showing a groove-binding mechanism. The stabilization of G4 by TPE-Im has been assessed by Fluorescence Resonance Energy Transfer (FRET) melting assays, which show a strong stabilization $\left(\Delta T_{1 / 2}\right.$ around $\left.+20^{\circ} \mathrm{C}\right)$, together with a specificity toward G4 with respect to double-stranded DNA.

Keywords: tetraphenylethene, G-quadruplexes, fluorescence, light-up probe, supramolecular

\section{INTRODUCTION}

G-quadruplexes (G4s) are secondary structures of DNA, formed by specific guanine-rich sequences in presence of monovalent cations. Guanine-rich sequences can self-assemble into square planar networks (called G-quartets) via Hoogsteen hydrogen-bonds, and these G-quartets can stack on top of each other, stabilized by monovalent alkali cations, to form G-quadruplexes (G4s) (Davis and Spada, 2007; Bochman et al., 2012; Doluca et al., 2013). Notably, it has been demonstrated that G4s are formed in human telomeres, made of DNA sequence d(TTAGGG)n (Balasubramanian and Neidle, 2009; Phan, 2010; Wu and Brosh, 2010; Lam et al., 2013; Hänsel-Hertsch et al., 2017). Telomeres are non-coding regions at the end of chromosomes that protect chromosomal ends from fusion during replication of DNA. A specific enzyme, the telomerase, add repetitions of $\mathrm{d}$ (TTAGGG)n at the end of telomeres, and it has been shown that in most cancer cells, this enzyme is overexpressed. The normal expression of telomerase into cells allows protection of 
coding genes during the cell life, whereas when telomerase is overexpressed, the cell can no longer enter into senescence and start multiplying in a non-controlled manner, causing tumor growth (Phan, 2010; Wu and Brosh, 2010; Biffi et al., 2013; Maji and Bhattacharya, 2014). The challenge that emerge from these hypotheses in anti-cancer drug design is designing molecules that can bind/stabilize G4s and inhibit the telomerase activity in tumor cells (Monchaud and Teulade-Fichou, 2008; Balasubramanian and Neidle, 2009; Collie and Parkinson, 2011; Tucker et al., 2012; Neidle, 2017; Asamitsu et al., 2019). A large number of small molecules, such as porphyrin, perylene, and naphthalene diimide derivatives, have been prepared and demonstrated their ability to bind G4 (Zhao et al., 2013; Golub et al., 2015; Rubio-Magnieto et al., 2015). We have notably studied the interaction between imidazolium- or pyridiniumbased tetracationic porphyrins and demonstrated their strong binding with G4s, and their selectivity to G4 over doublestranded DNA (dsDNA) (Rubio-Magnieto et al., 2015). Indeed, porphyrins have interesting UV-Vis absorption properties, but their fluorescence intensities in interaction with G4 are weak, hampering their use as fluorescent probes.

With the aim of evolving toward G4-DNA fluorescent probes, we synthesized a cationic tetraphenylethene (TPE) derivative, as recently reported by Hahn and coworkers (Sinha et al., 2017). The TPE core was selected due to its appropriate size in comparison to intramolecular human telomeric G4s (Hong et al., 2010). To promote multi-site interactions and solubility in aqueous media, four cationic groups were introduced into the TPE core as it has been achieved with porphyrins by us and others (Flynn et al., 1999; Trommel and Marzilli, 2001; Rubio-Magnieto et al., 2015). A remarkable characteristic of TPEs is their peculiar fluorescence properties: TPEs are poorly fluorescent when molecularly dissolved in solution due to the possible intramolecular rotations which lead to deexcitation through non-radiative pathways. However, when TPEs aggregate, a large increase of the fluorescence is noted because of the restriction of its intramolecular rotations by the aggregate formation (Mei et al., 2014; Yang et al., 2016). These AggregationInduced Emission (AIE) properties of TPE motivated us to conceive a "light-up" probe to stabilize and detect G4s with a very low detection limit. In contrast to another approach that make use of flexible alkylammonium groups (Hong et al., 2010; Zhang et al., 2015), we have selected imidazolium cationic groups directly connected to the TPE core (Scheme 1), as these were found to provide high affinity toward human telomeric G4s, through the combination of electrostatic interactions with the DNA backbone and $\pi$-type interactions with the nucleobases of the G4 loops (Rubio-Magnieto et al., 2015).

In this paper, we report on the synthesis and the optical properties of a novel compound TPE-Im, see Scheme 1. We study its G4 binding properties with human telomeric DNA (HT-DNA) sequences, by means of circular dichroism (CD), and fluorescence spectroscopies, and isothermal titration calorimetry (ITC). We have selected the (HT-DNA) sequences Tel22 (5'AGG GTT AGG GTT AGG GTT AGG G-3') because of their relevance as $\mathrm{G} 4$ targets in cancer research, and because

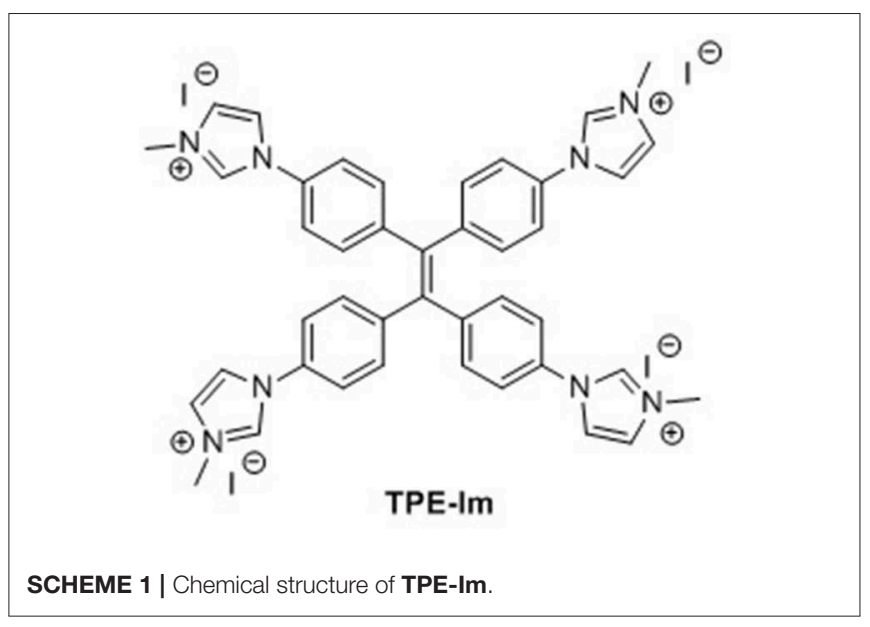

these sequences can adopt different intramolecular G-quadruplex structures depending on the solution conditions.

\section{MATERIALS AND METHODS}

\section{Materials}

Dry DMF and THF were obtained by a solvent purification system PureSolve MD5 from Innovative Technology. Preparative purifications were performed by silica gel flash column chromatography (Merck 40-60 mm). Solvents used as eluents are technical grade.

\section{Synthesis}

The synthesis of 1,1,2,2-tetrakis(4-bromophenyl)ethane (TPE-Br) was performed according to literature procedures (Schultz et al., 2003).

\section{Synthesis of Tetra-Imidazole-Appended Tetrakis( $\boldsymbol{p}$-phenylene)Ethylene (TIPE)}

1,1,2,2-tetrakis(4-bromophenyl)ethene $(0.500 \mathrm{~g}, 0,772 \mathrm{mmol}$ ), imidazole $(0.42 \mathrm{~g}, 6.177 \mathrm{mmol} ; 8$ eq.), potassium carbonate (0.750 g, 5.435 mmol; 7 eq.) and $\mathrm{CuSO}_{4}(0.025$ g, 0.157 mmol; 0.2 eq.) were placed into a Schlenk flask under an argon atmosphere and anhydrous DMF (2 mL) was added. The solid mixture was then heated to $140^{\circ} \mathrm{C}$ for $24 \mathrm{~h}$. The reaction mixture was cooled to room temperature and was washed three times $(3 \times 20 \mathrm{~mL})$ with distilled water. The remaining solid residue was extracted with methanol $(3 \times 10 \mathrm{~mL})$ and the methanol solution was filtered and evaporated under vacuum. The crude product was then purified by column chromatography on silica gel eluting with a gradient of dichloromethane:methanol (98:2-90:10) to give TIPE as a colorless solid. Yield: $0.220 \mathrm{~g}$ (0.370 mmol, $48 \%)$. Spectroscopic data for TIPE are the same as previously described in the literature (Sinha et al., 2017). ${ }^{1} \mathrm{H}$ NMR (300 MHz, DMSO$\left.d_{6}\right): \delta=8.27(\mathrm{~s}, 4 \mathrm{H}), 7.75(\mathrm{~s}, 4 \mathrm{H}), 7.54\left(\mathrm{~d},{ }^{3} J_{\mathrm{H}-\mathrm{H}}=8.5 \mathrm{~Hz}, 8 \mathrm{H}\right)$, $7.19\left(\mathrm{~d},{ }^{3} J_{\mathrm{H}-\mathrm{H}}=8.5 \mathrm{~Hz}, 8 \mathrm{H}\right), 7.09$ ppm (br. s, $\left.4 \mathrm{H}\right) \mathrm{ppm}$. 


\section{Synthesis of TPE-Im}

In a $50 \mathrm{~mL}$ Schlenk tube under an argon atmosphere, TIPE $(0.100 \mathrm{~g}, 0.168 \mathrm{mmol})$ was dissolved in anhydrous DMF $(15 \mathrm{~mL})$. Iodomethane ( $5 \mathrm{~mL}, 0.800 \mathrm{mmol} ; 470$ eq.) was added at once. The reaction mixture was stirred at room temperature for $72 \mathrm{~h}$. TPE-Im is then precipitated in diethyl ether $(400 \mathrm{~mL})$ and filtered leading to a yellow solid. Yield: $0.180 \mathrm{~g}(0.146 \mathrm{mmol}, 87 \%) .{ }^{1} \mathrm{H}$ NMR (300 MHz, CD 3 OD) $\delta=9.55(\mathrm{~s}, 4 \mathrm{H}), 8.05\left(\mathrm{t}, J_{\mathrm{H}-\mathrm{H}}=\right.$ $1.7 \mathrm{~Hz}, 4 \mathrm{H}), 7.76\left(\mathrm{t}, J_{\mathrm{H}-\mathrm{H}}=1.8 \mathrm{~Hz}, 4 \mathrm{H}\right), 7.61\left(\mathrm{~d},{ }^{3} J_{\mathrm{H}-\mathrm{H}}=8.7 \mathrm{~Hz}\right.$, $8 \mathrm{H}), 7.42\left(\mathrm{~d},{ }^{3} \mathrm{~J}_{\mathrm{H}-\mathrm{H}}=8.7 \mathrm{~Hz}, 8 \mathrm{H}\right), 4.03\left(\mathrm{~s}, 12 \mathrm{H}, \mathrm{N}-\mathrm{CH}_{3}\right) \mathrm{ppm}$. ${ }^{13} \mathrm{C}\left\{{ }^{1} \mathrm{H}\right\}$ NMR (101 MHz, CD $\left.{ }_{3} \mathrm{OD}\right) \delta=143.8,142.2,135.3$, 134.2, 125.7, 123.2, 122.6, 37.0 ppm. HR-MS (ESI-TOF $\left.{ }^{+}\right): m / z$ calculated $\mathrm{C}_{42} \mathrm{H}_{40} \mathrm{~N}_{8}^{4+} 164.0844[\mathrm{M}-4 \mathrm{I}]^{4+}$, found 164.0845. UVvis $\left(\mathrm{H}_{2} \mathrm{O}\right) \lambda\left(\varepsilon \mathrm{L} \cdot \mathrm{mol}^{-1} \cdot \mathrm{cm}^{-1}\right)=260$ (29 800), 293 (20 800), 322 (16 800) $\mathrm{nm}$.

\section{UV-Vis Absorption and Circular Dichroism Spectroscopy}

UV-Vis absorption spectra of pure TPE-Im were recorded at $25^{\circ} \mathrm{C}$ on a JASCO V-750 spectrophotometer in $10 \mathrm{~mm}$ quartz cells (Hellma). The extinction coefficients were determined by preparing solutions of TPE-Im at different concentration, and the concentration range was judiciously chosen to remain in the linear range of the Beer-Lambert relationship $(\mathrm{A} \sim$ 0.2-0.8). For TPE-Im/G4 mixtures, UV-Vis absorption and Circular Dichroism (CD) measurements were recorded using a ChirascanTM Plus CD Spectrometer from Applied Photophysics. The measurements were carried out using $2 \mathrm{~mm}$ suprasil quartz cells from Hellma Analytics. The spectra were recorded at $20^{\circ} \mathrm{C}$ between 225 and $600 \mathrm{~nm}$, with a bandwidth of $1 \mathrm{~nm}$, time per point $1 \mathrm{~s}$. The buffer water solvent was Tris-EDTA prepared from $1 \mathrm{M}$ Tris- $\mathrm{Cl}$ and $0.5 \mathrm{M}$ EDTA to achieve a $10 \mathrm{mM}$ Tris-Cl and $1 \mathrm{mM}$ EDTA final buffer at $\mathrm{pH}$ 7.5. The buffered water solvent reference spectra were used as baselines and were automatically subtracted from the CD and UV-Vis absorption of the samples. All the spectra were treated by using OriginPro 2018 software.

\section{Fluorescence Spectroscopy}

Emission spectra of pure TPE-Im were recorded at $25^{\circ} \mathrm{C}$ on a fluorescence spectrophotometer (FS920, Edinburgh Instruments) equipped with a calibrated photomultiplier in a Peltier (air cooled) housing (R928P, Hamamatsu), with a $450 \mathrm{~W}$ continuous xenon arc lamp as the excitation source for steady-state photoluminescence measurements using a quartz cuvette with $1.0 \mathrm{~cm}$ excitation path length. Emission spectra of TPE-Im/G4 mixtures were recorded using a ChirascanTM Plus CD spectrophotometer from Applied Photophysics equipped for fluorescence measurements. The measurements were carried out using $4 \mathrm{~mm}$ by $10 \mathrm{~mm}$ suprasil quartz cells from Hellma Analytics. The spectra were recorded at $20^{\circ} \mathrm{C}$ between 270 and $700 \mathrm{~nm}$, with a bandwidth of $2.0 \mathrm{~nm}$, time per point $0.5 \mathrm{~s}$. The buffer water solvent was Tris-EDTA at $10 \mathrm{mM}$ Tris-Cl and $1 \mathrm{mM}$ EDTA, pH 7.5, same as CD and UV-vis experiment. All the spectra were treated by using OriginPro 2018 software.

\section{Molecular Docking}

TPE-Im was built within the Avogadro molecular editor (Hanwell et al., 2012). Molecular mechanics calculations were then performed to optimize the geometry of the TPE-Im molecule. For this, a two-step minimization procedure, i.e., a steepest descent optimization followed by a conjugate gradient optimization, was performed with the General Amber Force Field (GAFF) (Wang et al., 2004). The energy convergence criterion was set at $10^{-5} \mathrm{~kJ}$. mol ${ }^{-1}$ for the energy minimization. The coordinates of the two G-quadruplexes (G4) were obtained from the Protein Data Bank (PDB ID: 143d and PDB ID: 2hy9). For each G4, we extracted the different NMR conformations to perform ensemble docking calculations, i.e., six conformations for the 143D target and 10 conformations for the $2 \mathrm{HY} 9$ target. Docking calculations were performed with the AutoDock Vina package (Trott and Olson, 2009). As we have no a priori knowledge of the TPE-Im binding mode along the G4 structures, a sufficiently large grid was built around each G4 structure to allow the exploration of the entire G4 surface during the docking calculations. A large grid size of $100 \times 100 \times 100 \AA^{3}$ with a spacing of $0.375 \AA$ was thus considered. The center of the grid box was located on the center-of-mass of the G4 targets. As the grid presents an important size, an exhaustiveness value of 32 was chosen, a larger one than the default value, i.e., eight (Jaghoori et al., 2016). TPE-Im was set as a flexible entity, and we considered various torsions between imidazolium and benzyl moieties. The 10 most energetically favorable complexes were retained for each docking calculation. The PyMOL molecular visualization system was used to depict illustrations of the TPEIm docking calculations (Delano, 2002).

\section{Fluorescence Resonance Energy Transfer (FRET) Melting Assays}

FRET melting assays were performed according to Decian et al. (2007), Renciuk et al. (2012), and Rubio-Magnieto et al. (2015), using a synthetic double-dye labeled oligonucleotide called F21T $5^{\prime}$-FAM-GGG(T2AG3)3-TAMRA-3' (purchased with the highest purity grade from Eurogentec, Belgium). The solutions were prepared at a concentration of around $0.3 \mu \mathrm{M}$ (ODN concentration) in $10 \mathrm{mM}$ lithium cacodylate buffer $(\mathrm{pH}=7.2)$ in presence of $100 \mathrm{mM} \mathrm{KCl}$. The solutions were first heated to $90^{\circ} \mathrm{C}$ for $315 \mathrm{~min}$ in the corresponding buffer conditions and then slowly cooled down at $1.5^{\circ} \mathrm{C} / \mathrm{min}$ to $20^{\circ} \mathrm{C}$ to support the formation of G4 secondary structure. The mixtures were equilibrated at $25^{\circ} \mathrm{C}$ during $5 \mathrm{~min}$. The FRET spectra were measured using a ChirascanTM Plus CD Spectrophotometer equipped for fluorescence measurements. The samples were excited at $492 \mathrm{~nm}$ and the fluorescence emission spectra were collected between 500 and $700 \mathrm{~nm}$. The temperature was varied from 20 to $95^{\circ} \mathrm{C}$ at a rate of $0.3^{\circ} \mathrm{C} / \mathrm{min}$. The melting of the F21T was monitored by measuring the fluorescence of FAM (at $516 \mathrm{~nm}$ ), as described in reference (Decian et al., 2007; Renciuk et al., 2012; Rubio-Magnieto et al., 2015). The FAM emission intensity was normalized and $\Delta \mathrm{T}_{1 / 2}$ was defined as the temperature for which the normalized emission equals 0.5 . For the selectivity studies, a solution of 10 molar equivalents of a 


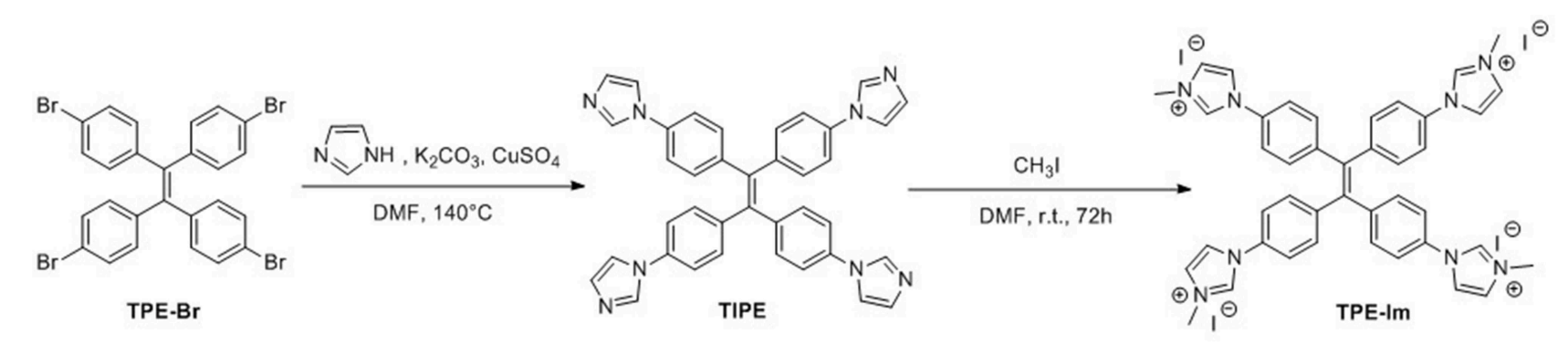

SCHEME 2 | Synthesis of TPE-Im.

dsDNA competitor ( $\sim 3 \mu \mathrm{M}$ in double-strand) was added into the F21T/TPE-Im solution and the final solution was equilibrated at $25^{\circ} \mathrm{C}$ during $5 \mathrm{~min}$. The dsDNA competitor (ds43) is a 43 base pairs with sequence: $5^{\prime}$-CGT CAC GTA AAT CGG TTA ACA AAT GGC TTT CGA AGC TAG CTT C-3', hybridized with its complementary sequence. All the spectra were treated by using OriginPro 2018 software.

\section{Isothermal Titration Calorimetry}

Isothermal titration calorimetry (ITC) experiments were carried out at $20^{\circ} \mathrm{C}$ on a Microcal ITC200 instrument (Microcal). The titration cell was filled with a solution of $10-20 \mu \mathrm{M}$ Tel22 DNA and the syringe was loaded with a TPE-Im solution of 600$2,000 \mu \mathrm{M}$. Experiments consisted of a series of 26 injections of ligand from rotating syringe (speed $750 \mathrm{rpm}$ ) into the thermostatic cell (initial delay of $60 \mathrm{~s}$, duration of $2 \mathrm{~s}$ and spacing of $120 \mathrm{~s}$ ). Control experiments were carried out where the ligand solution was added into the buffer containing cell. The corrected ITC titrations were treated by using Origin 7.0 software.

\section{RESULTS AND DISCUSSION}

\section{Synthesis}

TPE-bridged tetraimidazolium salt (TPE-Im) was synthesized in two steps starting from 1,1,2,2-tetrakis(4-bromophenyl)ethene (TPE-Br) by using a slightly modified version of a previously reported procedure (Scheme 2) (Sinha et al., 2017). First, the imidazole was linked to the TPE core through Ulmann coupling reaction leading to TIPE in $47 \%$ yield (Supplementary Figure 1). Then, the alkylation of TIPE with an excess of iodomethane afforded the tetraimidazolium salt in a quantitative yield (Supplementary Figures 2, 3). The ${ }^{1} \mathrm{H}$ NMR spectrum of TPEIm in $\mathrm{CD}_{3} \mathrm{OD}$ clearly shows the downfield signal of the acidic proton $(\mathrm{C}-\mathrm{H})$ of the imidazolium ring at $\delta=9.55 \mathrm{ppm}$ and the signal of $\mathrm{N}_{-} \mathrm{CH}_{3}$ at $\delta=4.03 \mathrm{ppm}$ (see Supplementary Figure 2). The molecular mass peak of TPE-Im was observed by using ESITOF mass spectrometry at $m / z=164.0845$, as expected for this tetracationic species (calculated $m / z=164.0844[\mathrm{M}-4 \mathrm{I}]^{4+}$ ).

\section{Optical Properties}

The optical properties of TPE-Im were studied by UV-Vis absorption and photoluminescence (PL) spectroscopies. The absorption and emission spectra of TPE-Im in water $(0.8 \%$
DMSO) are shown in Figure 1A. Two unstructured absorption bands are observed at $293 \mathrm{~nm}$ and $322 \mathrm{~nm}$, which could be assigned to $\pi-\pi^{*}$ transition (Salimimarand et al., 2017; Kayal et al., 2018). In water, TPE-Im shows two emission bands: a structured one at $\sim 380 \mathrm{~nm}$ and another broader and weaker at $\sim 480 \mathrm{~nm}$. The shape of the emission spectra, especially the ratio of the intensity of the two bands at $\sim 380 \mathrm{~nm}$ and $\sim 480 \mathrm{~nm}$, is dependent on the nature of the solvent. Figure 1B shows the emission spectra of TPE-Im in polar aprotic (acetonitrile, DMF, DMSO) and protic $(\mathrm{MeOH})$ solvents. A strong increase of the emission band at $\sim 480 \mathrm{~nm}$ in the emission spectra of TPE-Im in pure DMSO is noticed compared to water ( $0.8 \%$ DMSO). To understand the nature of the band at longer wavelength, the effect of concentration on the emission profile of pure TPE-Im in water is studied (from $10^{-5}$ to $10^{-3} \mathrm{M}$, see Figure $1 \mathrm{C}$ ). At high concentration $\left(5 \times 10^{-4}-10^{-3} \mathrm{M}\right)$, only the broad emission band at longer wavelength remains but its intensity gradually decreases. The solvatochromic and concentration effects may indicate that the broad peak at around $470 \mathrm{~nm}$ is due to a twisted intramolecular charge transfer (TICT) state, as previously observed for tetrapyridinium-based TPE (Grabowski et al., 2003; Shigeta et al., 2012). To investigate the potential AIE behavior of TPE-Im, emission spectra were then recorded in water/THF mixtures with different THF fractions in view of fine-tuning the THF content as well as the aggregation extent (Figure 1D). Adding a poorer solvent (THF) to the water solution results in the gradual disappearance of the broad emission band around $380 \mathrm{~nm}$. Only the broad emission band around $480 \mathrm{~nm}$ remains at high THF content (90\%). However, adding THF to a solution of TPE-Im in water not only leads to a modification of the emission profile but also to an important decrease of the emission intensity. These results clearly indicate that TPE-Im is AIEinactive in THF/water solution conditions.

DFT B3LYP $6 / 31 G^{*}$ calculations have been carried out on TPE-Im to both get information about its optimized structure and its frontier orbitals plots (Frisch et al., 2009). As observed with other TPE derivatives, the optimized structure shows a four-winged propeller-like conformation with slightly different torsion angles between the ethylene core and the adjacent phenyl rings in the range of what is usually measured from the crystals $\left(\varphi_{1}=52.0^{\circ}, \varphi_{2}=52.9^{\circ}, \varphi_{3}=50.1^{\circ}, \varphi_{4}=53.8^{\circ}, \varphi_{\mathrm{av}}=\right.$ $52.2^{\circ}$ ) (Supplementary Figure 4 and Supplementary Table 1) (Cai et al., 2018; Zhang et al., 2019). Examination of the frontier 

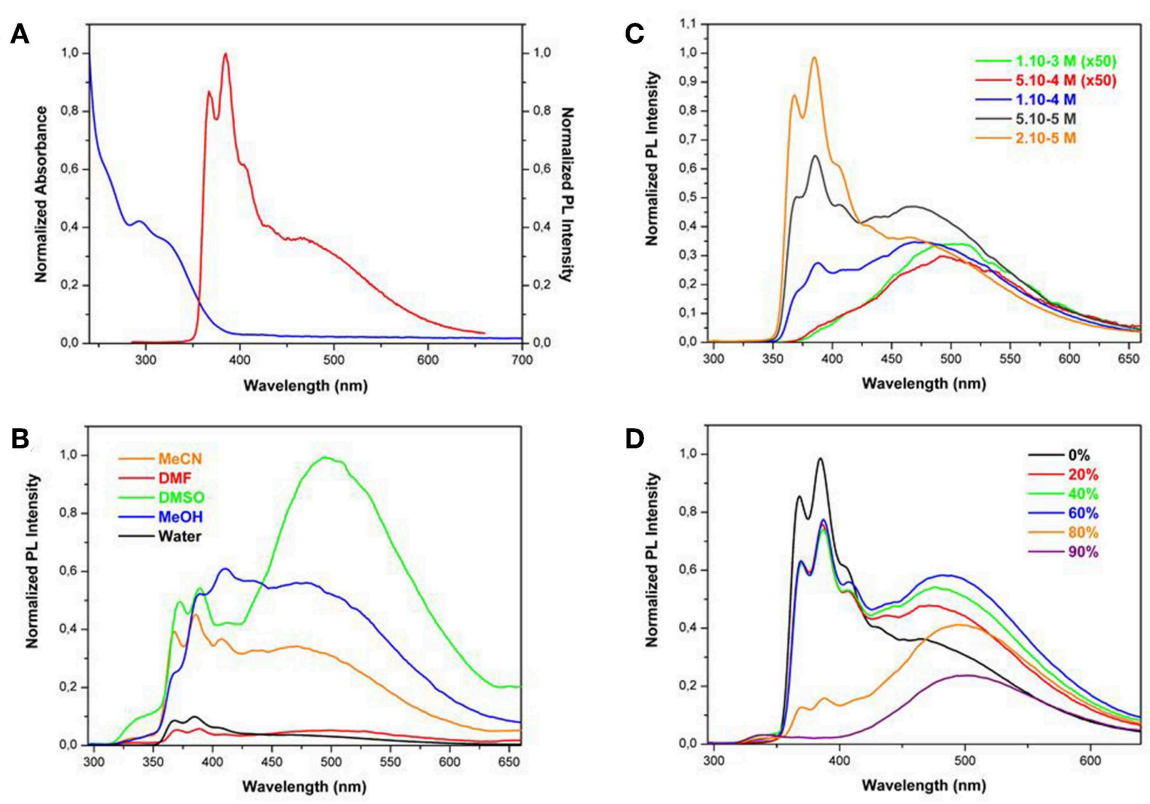

FIGURE 1 | (A) UV-Visible absorption (blue) and PL spectra (red) of TPE-Im in water (0.8 \% DMSO) at $2 \times 10^{-5} \mathrm{M}$ ( $\lambda$ exc $\left.=265 \mathrm{~nm}\right)$. (B) PL spectra of TPE-Im in water (black), methanol (blue), acetonitrile (orange), DMF (red), and DMSO (green) at $2 \times 10^{-5} \mathrm{M}\left(\lambda_{\text {exc }}=265 \mathrm{~nm}\right)$. (C) PL spectra of TPE-Im at different concentrations ( $\lambda_{\text {exc }}=265 \mathrm{~nm}$ ). (D) PL spectra of TPE-Im in water/THF mixtures with different THF fractions (Concentration: $\left.2 \times 10^{-5} \mathrm{M}, \lambda_{\text {exc }}=265 \mathrm{~nm}\right)$.
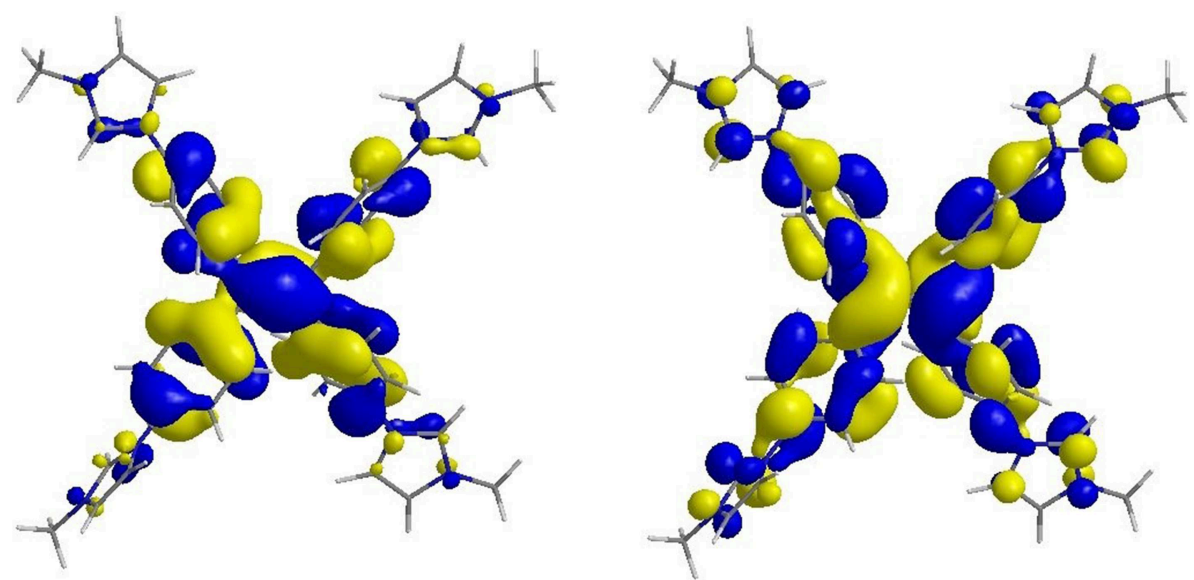

FIGURE 2 | Isosurface plots of frontier orbitals in the ground state: HOMO (left) and LUMO (right) orbitals of TPE-Im.

orbital plots indicates that HOMO and LUMO orbitals are mainly located on the TPE core with a relatively low contribution of the imidazolium rings, which suggests that the photophysical properties mainly arise from the TPE core (Figure 2).

\section{Binding to Human Telomeric Sequence}

The human telomeric sequence studied here was Tel22 of $\mathrm{d}\left[\mathrm{AG}_{3}\left(\mathrm{~T}_{2} \mathrm{AG}_{3}\right)\right]$ sequence, which presents different $\mathrm{G} 4$ loop structures depending on the nature of the alkali cation added in solution. With $\mathrm{Na}^{+}$at $100 \mathrm{mM}$, Tel22 specifically folds into G4 parallel loop structure. In contrast, with $\mathrm{K}^{+}$at $100 \mathrm{mM}$, it folds into a mixture of parallel and anti-parallel
G4 conformation, in a dynamic equilibrium between hybrid structures (Dai et al., 2008; Phan, 2010). CD spectra of TPEIm in interaction with different Tel22 in different aqueous solution media are presented in Figure 3. The CD spectra of Tel22 in presence of $\mathrm{KCl}$ show a positive peak at $290 \mathrm{~nm}$ and a shoulder at $250 \mathrm{~nm}$, which is typical of Tel22 with $\mathrm{K}^{+}$ (Rubio-Magnieto et al., 2015). In the TPE-Im/Tel22 mixture (5:1), the CD bands related to the G-quadruplex are barely modified, with a slight decrease of the signal intensity. A weak negative peak appears at $315 \mathrm{~nm}$, in the spectral range where only TPE-Im absorbs. Indeed, pure TPE-Im in aqueous solution does not show any CD signal. CD spectra of Tel22 


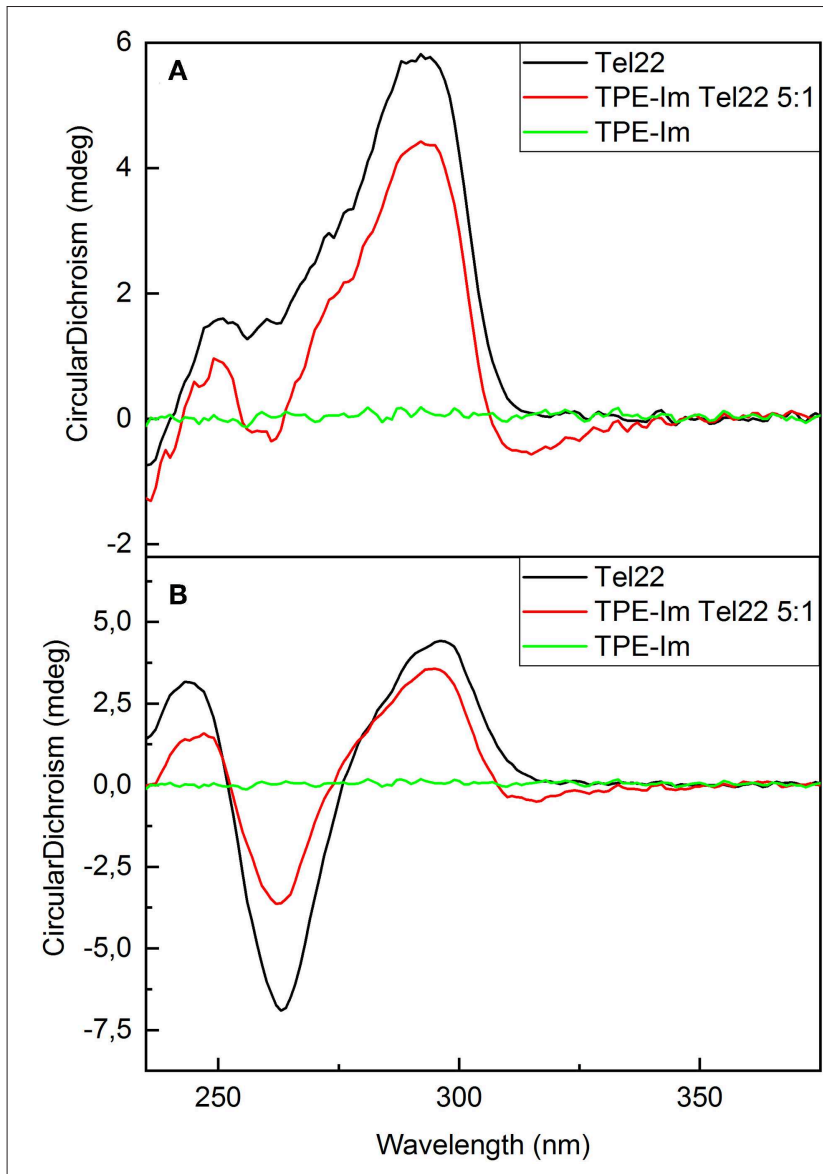

FIGURE 3 | CD spectra of (A) TPE-Im:Tel22 in TE buffer $+100 \mathrm{mM} \mathrm{KCl}$; B) TPE-Im:Tel22 in TE buffer $+100 \mathrm{mM} \mathrm{NaCl}$. The molar ratio for $(\mathbf{A})$ and $\mathbf{( B )}$ is 5:1 in TPE-Im:Tel22.

in aqueous solution with $\mathrm{NaCl}$ show specific antiparallel Gquadruplex structure, with a positive peak at $295 \mathrm{~nm}$ and strong negative peak at $265 \mathrm{~nm}$ (Wang and Patel, 1993; Rubio-Magnieto et al., 2015). These signals are reduced in presence of TPEIm, and a very weak negative signal at $315 \mathrm{~nm}$ is present. As the concentration of Tel22 is maintained constant for both experiments (see Supplementary Figure 5), the modifications in the spectra seem to be directly linked to the interaction between TPE-Im and Tel22.

\section{Molecular Modeling of TPE/G4 Binding Modes}

To gain insights into the affinity and the binding modes of TPE-Im with Tel22, we perform docking calculations using the AutoDock Vina package (Trott and Olson, 2009), see computational details in the Supporting Information. We consider several conformations for both G4 targets (six conformations for the PDB IDs 143D with $\mathrm{Na}^{+}$, and 10 conformations for $2 \mathrm{HY} 9$ with $\mathrm{K}^{+}$) to take into account, in an implicit manner, the flexibility of the targets. The affinity, calculated on the 10 most stable docking solutions for each conformation of both G4 targets, are reported in Supplementary Figure 10. In Supplementary Table 2, we report the statistical analysis of the related docking calculations. For the G4 target in $\mathrm{K}^{+}$(2HY9), the best average affinity is found for the third conformation (model 3 in the NMR structure), with the global maximal affinity (lowest binding energy) of $E_{b}=-7.3 \mathrm{kcal} / \mathrm{mol}$ (corresponding to the structure shown in Figure 4 top). Let us note that the average RMSD of the 10 recorded docking solutions is also the lowest for the third conformation, which emphasizes a stable binding mode. For the G4 target in $\mathrm{Na}^{+}$(143D), the most stable set of docking solutions is found for the conformation \#5 $\left(E_{b}=-7.1 \mathrm{kcal} / \mathrm{mol}\right.$, Supplementary Figure 10 and Supplementary Table 2), see its structure in Figure 4 bottom.

The most energetically favorable docking solutions for TPEIm/Tel22 complex present similar calculated binding energies $\left[E_{b}=-7.3 \mathrm{kcal} / \mathrm{mol}\right.$ for the TPE-Im/G4(2HY9) complex and $E_{b}=-7.1 \mathrm{kcal} / \mathrm{mol}$ for the TPE-Im/G4(143D)]. However, the superpositions of the 10 most stable docking solutions (Supplementary Figures 11, 12) depict different TPE-Im/G4 binding modes depending on the alkali cation. For the $2 \mathrm{HY} 9$ G4, docking solutions are well-superposed, indicating one clear binding mode of TPE-Im (Supplementary Figure 11). Nine of the ten TPE-Im/G4 (2HY9) docking solutions are grouped into only two clusters (Supplementary Figure 11). Moreover, these two clusters are similar between them regarding the weak RMSD value with respect to the most stable docking solution (Supplementary Table 3). Therefore, docking calculations show that TPE-Im ligand has a single, well-defined binding mode, as shown in Figure 4 with TPE-Im buried at the bottom of the 2 HY9 target. The close contacts of the most stable docking solution show that the charged nitrogen atoms of TPE-Im ligand are close to the phosphate groups of $2 \mathrm{HY} 9$. A proximity between aromatic nucleobases and aromatic ligand moieties is also observed. The affinity of the TPE-Im ligand to the G4 target (2HY9) arises from concomitant electrostatic interactions and stacking interactions.

The possible binding modes are different for the second G4 target (PDB ID: 143D). Although the TPE-Im is also bound in a wide groove of $143 \mathrm{D}$, the 10 docking solutions are clearly much less superimposed than for $2 \mathrm{HY}$, illustrating various binding modes. The docking solutions are therefore grouped into clusters (Supplementary Figure 12), with high differences in RMSD values (Supplementary Table 4) compared to the case of TPE-Im/G4(2HY9) complex. The close contacts of the most stable docking mode do not involve phosphate groups (see Figure 4 bottom), and the aromatic moieties of the TPE-Im are not in contact with nucleobases, with a quasi-perpendicular binding mode between the G4(143D) tetrad and the main plane of TPE-Im. Such a binding mode explains why the affinity of the TPE-Im ligand with the 143D target is lower compared to the $2 \mathrm{HY} 9$ target. Let us note that the most stable docking solution of TPE-Im/G4(143D) implies a particular conformation of the G4(143D) target, i.e., an opening of the G4 structure through disruption of some interactions between nucleobases. The docking calculations do not take into account the entropic effects, but such a binding mode could have a high entropic 


\section{2hy9}

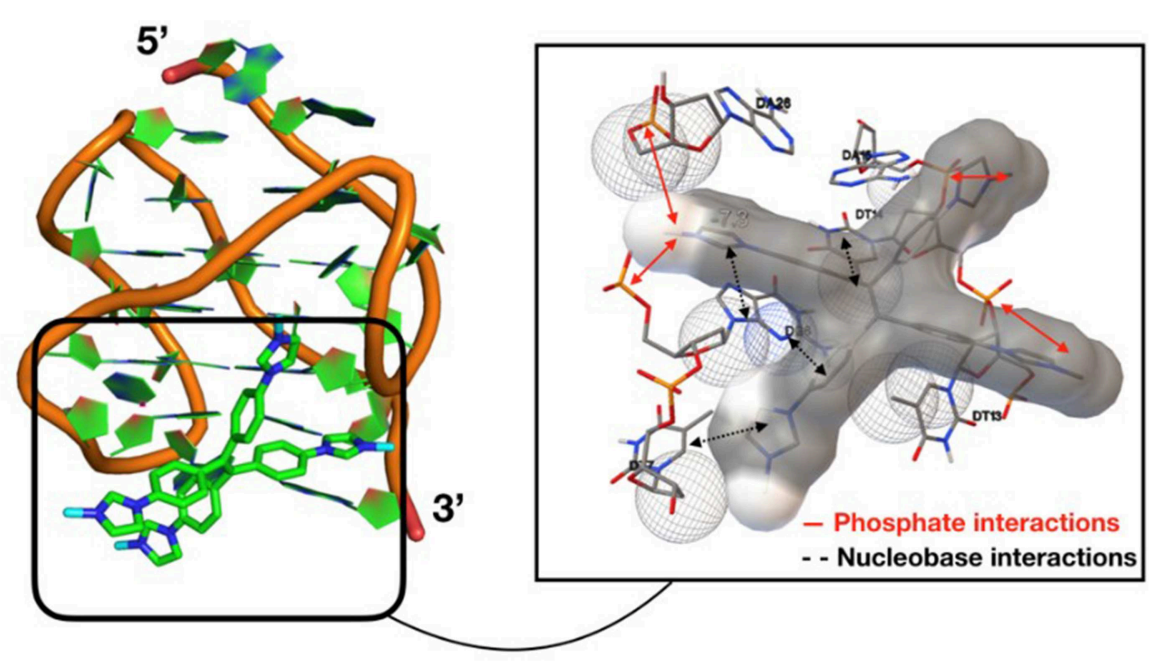

\section{$143 d$}

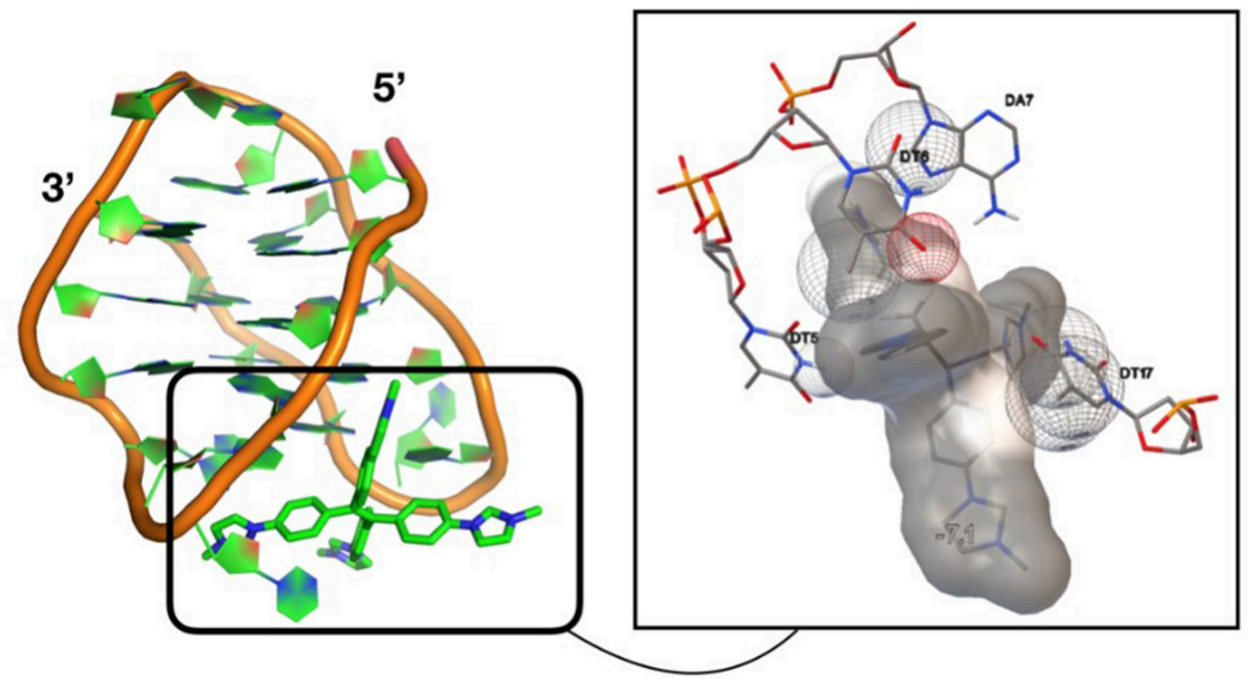

FIGURE 4 | Structures of the most stable docking solutions for each G4 target (see PDB ID on the left). The close contacts are shown on the right, with TPE-Im surrounded by its van der Waals surface. The spheres in dots represent van der Waals spheres of the atoms of G4 in contact with the TPE-Im ligand.

cost, needing an opening of $143 \mathrm{D}$. These docking calculations indicate a groove-binding mechanism of TPE-Im to HT-G4, with more diverse possible binding modes for $2 \mathrm{HY} 9 \mathrm{G} 4$ compared to $143 \mathrm{D}$ G4.

\section{Fluorescence Spectroscopy of TPE/G4}

The interactions between TPE-Im and Tel22 have also been studied by fluorescence spectroscopy, as shown in Figure 5. Pure TPE-Im in TE buffer (black lines Figure 5) reaches an emission maximum at $390 \mathrm{~nm}$, with a broad shoulder at $470 \mathrm{~nm}$. In the presence of salt or in physiological environment buffer, only minor changes are observed in the emission profile compared to pure TPE-Im: the intensity of the emission band at $390 \mathrm{~nm}$ is slightly modified whereas the emission band at $470 \mathrm{~nm}$ shows the same intensity with or without $\mathrm{KCl}$ in the solution (Supplementary Figures 6,7). Adding Tel22 to a solution containing $\mathrm{NaCl}$, the emission peak at $470 \mathrm{~nm}$ of
TPE-Im strongly increases while the peak at $390 \mathrm{~nm}$ vanishes. This increase of fluorescence for TPE-Im may be due to the concomitant electrostatic interactions and stacking interactions taking place with G4 (see above), which leads to restricted intramolecular rotations and thus, an exalted emission band around $480 \mathrm{~nm}$; a typical value for TPE derivatives in aggregated state (Huang et al., 2012; Odabas et al., 2013; Sinha et al., 2017). The same behavior is observed with Tel22 in an aqueous solution containing $\mathrm{KCl}$, the shoulder at $390 \mathrm{~nm}$ decreases while the peak at $470 \mathrm{~nm}$ strongly increases, with about the same intensity than with $\mathrm{NaCl}$. This "light-up" fluorescence effect is influenced by the presence of added salt in the mixture. Indeed, the increase of the fluorescence is significantly higher when no salt is added (note that pure Tel22 form G-quadruplex structures even without adding salt to the solution, see Supplementary Figure 8), while it is lower with a concentration of added salt at $100 \mathrm{mM}$ of $\mathrm{NaCl}$ or $\mathrm{KCl}$ (see green lines vs. red lines in Figure 5, respectively). 


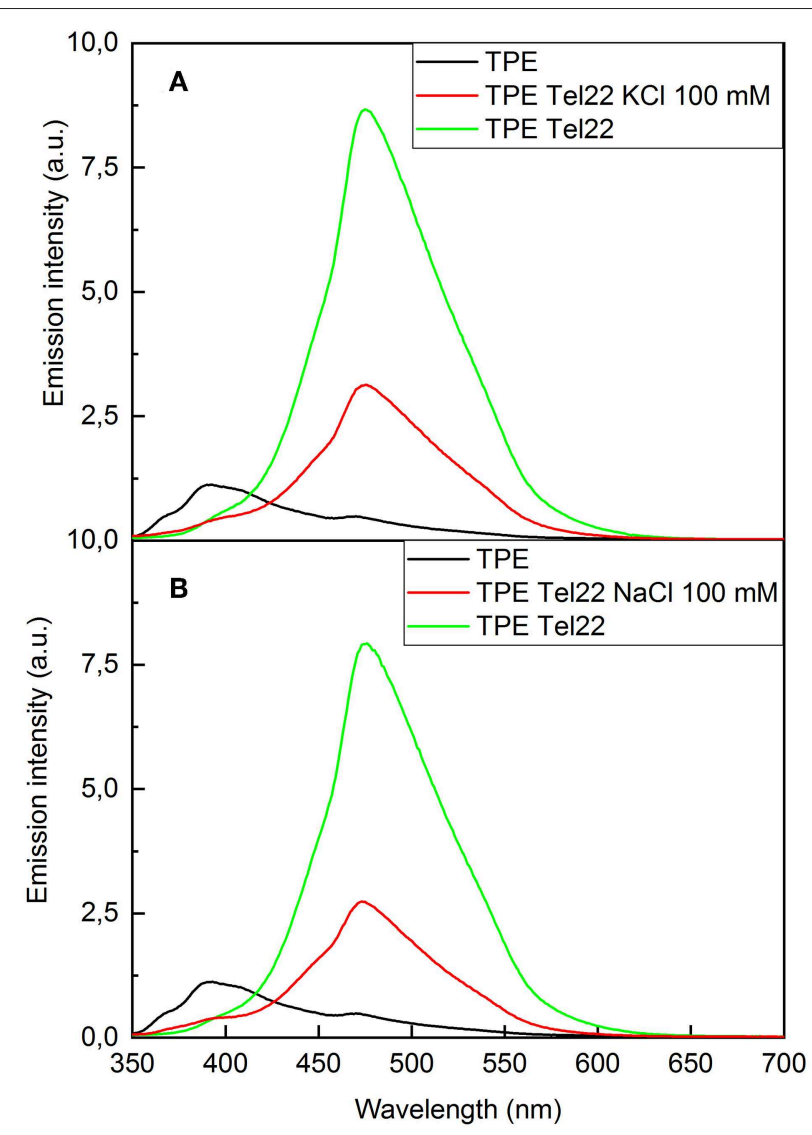

FIGURE 5 | Fluorescence spectra of (A) TPE-Im:Tel22 in TE buffer ( $\lambda_{\text {exc }}=$ $265 \mathrm{~nm})$. (B) TPE-Im:Tel22 in TE buffer $\left(\lambda_{\text {exc }}=265 \mathrm{~nm}\right)$. The molar ratio for (A) and (B) is 5:1 in TPE-Im:Tel22.

It is likely that G4 binding and further aggregation of TPEIm over G4 is more favorable when the concentration of alkali cations is low, with a lesser extent of screening by alkali ions than for solutions with $100 \mathrm{mM}$ of added salt. The selectivity of TPE-Im toward double stranded DNA ( $\left.\mathbf{d s R}_{\mathbf{2 0}}\right)$ vs. G4 DNA (Tel22) was estimated through fluorescence measurements. Adding Tel22 to TPE-Im results in a fluorescence exaltation three or five times higher than that with double-stranded DNA (see Supplementary Figure 9).

\section{Stability and Specificity of TPE/G4 Interaction}

Fluorescence Resonance Energy Transfer (FRET) melting assays were performed in order to assess the stability and selectivity of TPE-Im for G-quadruplex over double-stranded DNA (dsDNA). These experiments are based on the measurement of the melting temperature of double-dye labeled G4, by monitoring the FRET between two dyes located at $5^{\prime}$ and $3^{\prime}$ positions when the G4 goes from folded to unfolded states upon increasing the temperature of the solution. The oligonucleotide used here is a modified Tel22 sequence end-capped with a fluorescein amidite dye (FAM) at $5^{\prime}$-end and a tetramethylrhodamine (TAMRA)

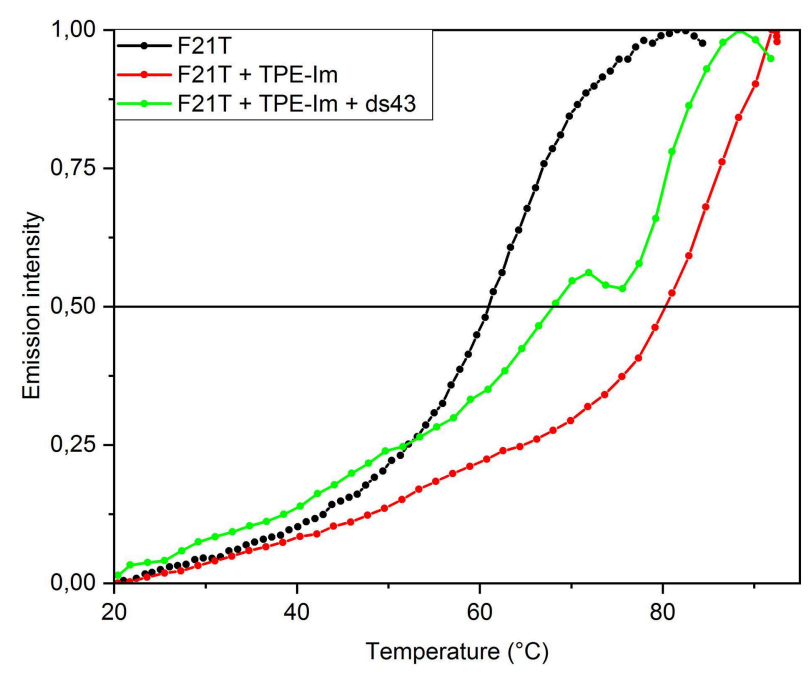

FIGURE 6 | FRET melting essay for solutions of pure F21T (200 nM), and in the presence of $1 \mu \mathrm{M}$ TPE-Im with or without 10 equivalent of competitor double-stranded DNA (ds43). The emission intensity corresponds to normalized FAM fluorescence $\left(\lambda_{\text {exc }}=492 \mathrm{~nm}\right)$. All measurements were performed in a $10 \mathrm{mM}$ lithium cacodylate buffer $(\mathrm{pH}=7.2)$ with $100 \mathrm{mM} \mathrm{KCl}$.

at $3^{\prime}$-end, the labeled oligonucleotide FAM-5'-GGG(T2AG3)3TAMRA-3', referred to as F21T. This oligonucleotide has been widely studied in the literature for assessing stabilization of G4 and selectivity by ligands (Decian et al., 2007; Renciuk et al., 2012). After a preliminary heating/cooling cycle of F21T to make sure of its folding into a G4, TPE-Im is added and the emission of the donor dye (i.e., FAM, $\lambda_{\text {exc }}=492 \mathrm{~nm}$ ) has been followed as a function of temperature, as it has already been done by us and others. This method has been shown to give more reproducible results than the sensitized emission of the acceptor (i.e., TAMRA). The G4 structure unfolds when the temperature increases and thereby the light emission of the donor (i.e., FAM) increases. The denaturation of $\mathrm{G} 4$ has been followed for pure F21T, for a mixture F21T/TPE-Im in a 1:5 molar ratio, and for a mixture F21T/TPE-Im/ds43 in a 1:5:10 molar ratio in $\mathrm{K}^{+}$buffer conditions, as shown in Figure 6. The determination of the half-melting temperature difference $\left(\Delta \mathrm{T}_{1 / 2}\right)$ between the pure F21T and F21T/TPE-Im is a quantitative measurement of the stabilization effect due to the added ligand. The results show $\mathrm{T}_{1 / 2}$ of 61.0 and $80.5^{\circ} \mathrm{C}$ for the pure F21T and TPEIm/F21T, respectively. These results show a strong stabilization of G-quadruplex by TPE-Im, with a $\Delta \mathrm{T}_{1 / 2}=19.5^{\circ} \mathrm{C}$. The addition of 10 equivalents of dsDNA competitor (ds43) disturbs the TPE-Im/F21T stabilization, with a $\mathrm{T}_{1 / 2}$ of $68^{\circ} \mathrm{C}$ $\left(\Delta \mathrm{T}_{1 / 2}=7^{\circ} \mathrm{C}\right)$, despite the high content in competitor. This means that TPE-Im is more specific to Tel22 G4 DNA conformation than to dsDNA conformation, even with 10 times the concentration of double-stranded DNA vs. G4 DNA. The TPE-Im/F21T complex seems disturbed by the high concentration on competitive double stranded DNA but we cannot see a complete drawback to pure F21T $\mathrm{T}_{1 / 2}$. In comparison with the previous work of our group, the 

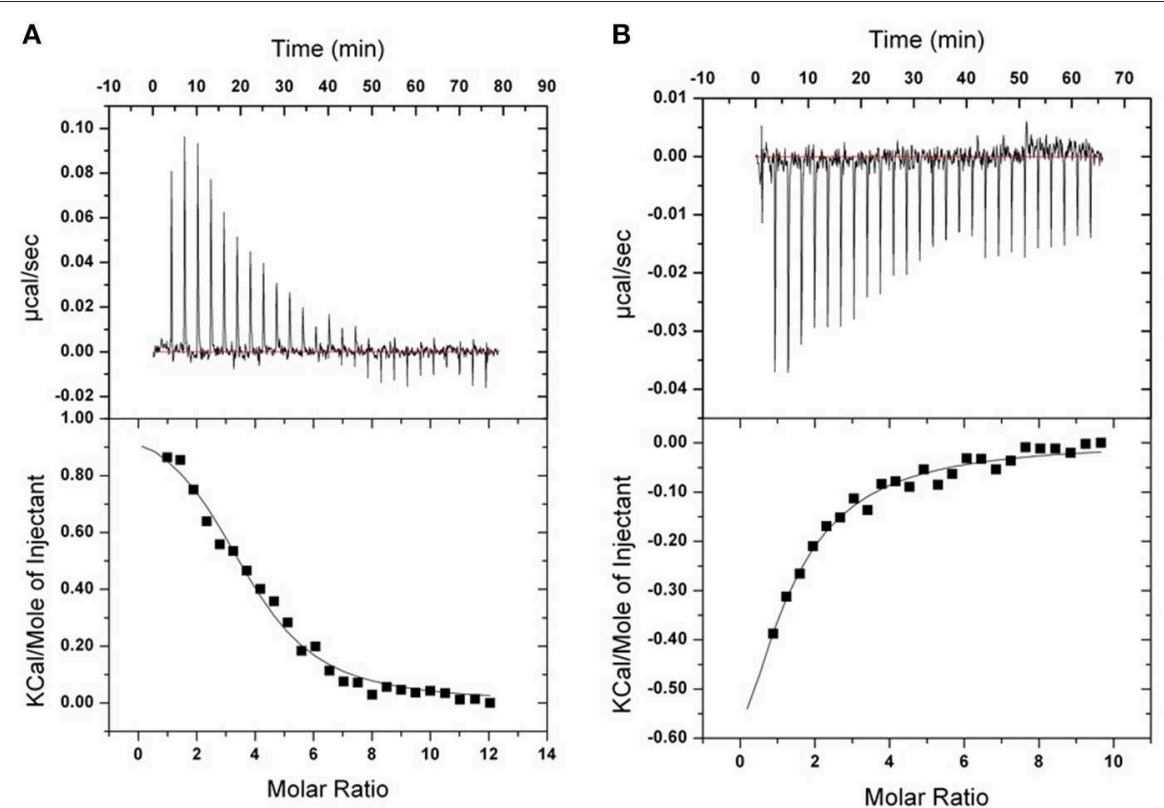

FIGURE 7 | ITC binding isotherms obtained at $20^{\circ} \mathrm{C}$ for TPE-Im in two different buffers. (A) $10 \mathrm{mM}$ Tris, $1 \mathrm{mM} \mathrm{EDTA}, 100 \mathrm{mM} \mathrm{KCl,} \mathrm{pH} 7.4$. (B) $10 \mathrm{mM}$ Tris, $1 \mathrm{mM}$ EDTA, $100 \mathrm{mM} \mathrm{NaCl}, \mathrm{pH}$ 7.4. The upper isotherms indicate Tel22 DNA binding raw data. The lower curves are obtained after integration of individual heat flow signals as function of DNA/ligand molar ratio in the calorimeter cell.

TABLE 1 | Estimates of the association constants $K_{a}$ and thermodynamic parameters, as determined by ITC.

\begin{tabular}{lcc}
\hline & \multicolumn{2}{c}{ TPE-Im/HT-G4 } \\
\cline { 2 - 3 } & in NaCl & in $\mathbf{~ C l}$ \\
\hline$K_{a}\left(\mathrm{M}^{-1}\right)$ & $3.2( \pm 1.1) \cdot 10^{5}$ & $2.4( \pm 1.0) \cdot 10^{5}$ \\
$\Delta \mathrm{H}\left(\mathrm{kcal} . \mathrm{mol}^{-1}\right)$ & $-0.3( \pm 0.06)$ & $0.8( \pm 0.1)$ \\
$-\mathrm{T} \Delta \mathrm{S}\left(\mathrm{kcal} . \mathrm{mol}^{-1} \cdot \mathrm{K}^{-1}\right)$ & $-7.1( \pm 0.2)$ & $-8( \pm 0.2)$ \\
\hline
\end{tabular}

TPE-Im/F21T complex is less disrupted than the porphyrin's one (Rubio-Magnieto et al., 2015). It is likely due to its geometry that is particularly adapted to the G4 structure (see above). Note that we observe a jump in the green curve at $72^{\circ} \mathrm{C}$ which may be due to a partial intercalation of TPE-Im in the unwound double stranded DNA (that has a melting temperature slightly under at $\left.67^{\circ} \mathrm{C}\right)$.

\section{Isothermal Titration Calorimetry}

Isothermal titration calorimetry experiments were carried out to quantify the binding of TPE-Im to Tel22 DNA in presence of $\mathrm{NaCl}$ or $\mathrm{KCl}$, see Figure 7 and Table 1. In both cases, binding seems to be strongly driven by favorable entropy changes to a much greater extent than with the flexible cationic TPE-based ligands previously described (Hong et al., 2010). This different behavior is possibly due to the dehydration of the larger aromatic surface of TPE-Im whereas entropic penalty occurs upon binding for the TPE-derivatives having flexible side-chains. While a small favorable enthalpy change is observed in the presence of $\mathrm{NaCl}$, an endothermic binding occurs in the presence of $\mathrm{KCl}$. It is possible that this small difference is due to the better pre-organization of Tel22 in a single G4 parallel loop structure with $\mathrm{NaCl}$ and in a mixture of parallel and anti-parallel G4 conformation with $\mathrm{KCl}$, but we interpret this with caution because of the small difference of measured association constants. Overall, the observed association constants reach $3.2 \pm 1.110^{5} \mathrm{M}^{-1}$ in $\mathrm{NaCl}$ and $2.4 \pm 1.010^{5} \mathrm{M}^{-1}$ in $\mathrm{KCl}$ (Figure 7), which are typical of TPE-based G-quadruplex ligands (Hong et al., 2010).

\section{CONCLUSIONS}

We have reported on the design of a novel TPE-based fluorophore that features methyl-imidazolium groups directly tethered to the TPE core, TPE-Im. We found that this original design endows peculiar optical properties and a significant shift from 380 to $480 \mathrm{~nm}$ in the fluorescence emission that is triggered by aggregation. Binding to a (HT-DNA) sequences Tel22 was characterized by $\mathrm{CD}$ spectroscopy without and with salts $(\mathrm{NaCl}$, $\mathrm{KCl}$ ), and molecular modeling suggest a predominant side-on groove binding, with an opening of the grooves in the case of Tel22 in KCl. Fluorescence spectroscopy demonstrates that the probe TPE-Im shows a turn-on fluorescence emission upon binding to Tel22, and interestingly, also displays a significant shift in fluorescence emission (380 to $480 \mathrm{~nm}$ ). A FRET melting assay shows a strong stabilizing effects of TPE-Im on the secondary folded structure of Tel22 $\left(\Delta \mathrm{T}_{1 / 2}=19.5^{\circ} \mathrm{C}\right)$, with a good degree of selectivity to G4 against double-stranded DNA. Finally, ITC was used to determine the association constants, which are in the range $2.4-3.2 \times 10^{5}$ depending on the solution conditions. Overall, we believe these results set the stage for the further use of TPE-Im as a novel probe that display turn-on and ratiometric responses upon binding to DNA G-quadruplexes. 


\section{DATA AVAILABILITY}

The raw data supporting the conclusions of this manuscript will be made available by the authors, without undue reservation, to any qualified researcher.

\section{AUTHOR CONTRIBUTIONS}

All authors listed have made a substantial, direct and intellectual contribution to the work, and approved it for publication.

\section{FUNDING}

Research in Mons was supported by the University of MonsUMONS and by the Fund for Scientific Research (F.R.S.FNRS), under the grants MIS No. F.4532.16 (SHERPA) and

\section{REFERENCES}

Asamitsu, S., Bando, T., and Sugiyama, H. (2019). Ligand design to acquire specificity to intended G-quadruplex structures. Chem. Eur. J. 25, 417-430. doi: 10.1002/chem.201802691

Balasubramanian, S., and Neidle, S. (2009). G-quadruplex nucleic acids as therapeutic targets. Curr. Opin. Chem. Biol. 13, 345-353. doi: $10.1016 /$ j.cbpa.2009.04.637

Biffi, G., Tannahill, D., McCafferty, J., and Balasubramanian, S. (2013). Quantitative visualization of DNA G-quadruplex structures in human cells. Nat. Chem. 5, 182-186. doi: 10.1038/nchem.1548

Bochman, M. L., Paeschke, K., and Zakian, V. A. (2012). DNA secondary structures: stability and function of G-quadruplex structures. Nat. Rev. Genet. 13, 770-780. doi: 10.1038/nrg3296

Cai, Y., Du, L., Samedov, K., Gu, X., Qi, F., Sung, H. H. Y., et al. (2018). Deciphering the working mechanism of aggregation-induced emission of tetraphenylethylene derivatives by ultrafast spectroscopy. Chem. Sci. 9, 4662-4670. doi: 10.1039/C8SC01170B

Collie, G. W., and Parkinson, G. N. (2011). The application of DNA and RNA G-quadruplexes to therapeutic medicines. Chem. Soc. Rev. 40, 5867-5892. doi: $10.1039 / \mathrm{clcs} 15067 \mathrm{~g}$

Dai, J., Carver, M., and Yang, D. (2008). Polymorphism of human telomeric quadruplex structures. Biochimie 90, 1172-1183. doi: 10.1016/j.biochi.2008.02.026

Davis, J. T., and Spada, G. P. (2007). Supramolecular architectures generated by self-assembly of guanosine derivatives. Chem. Soc. Rev. 36, 296-313. doi: 10.1039/B600282J

Decian, A., Guittat, L., Kaiser, M., Saccà, B., Amrane, S., Bourdoncle, A., et al. (2007). Fluorescence-based melting assays for studying quadruplex ligands. Methods 42, 183-195. doi: 10.1016/j.ymeth.2006.10.004

Delano, W. L. (2002). The PyMOL Molecular Graphics System. Available online at: https://ci.nii.ac.jp/naid/10020095229/en/

Doluca, O., Withers, J. M., and Filichev, V. V. (2013). Molecular engineering of guanine-rich sequences: Z-DNA, DNA triplexes, and G-Quadruplexes. Chem. Rev. 113, 3044-3083. doi: 10.1021/cr300225q

Flynn, S. M., George, S. T., White, L., Devonish, W., and Takle, G. B. (1999). Water-soluble, meso-substituted cationic porphyrins-a family of compounds for cellular delivery of oligonucleotides. BioTechniques 26, 736-746. doi: 10.2144/99264rr03

Frisch, M. J., Trucks, G. W., Schlegel, H. B., Scuseria, G. E., Robb, M. A., Cheeseman, J. R., et al. (2009). Gaussian 09, Revision A.02. Wallingford CT: Gaussian, Inc.

Golub, E., Lu, C.-H., and Willner, I. (2015). Metalloporphyrin/G-quadruplexes: from basic properties to practical applications. J. Porphyr. Phthalocyan. 19, 65-91. doi: 10.1142/S1088424615300025
EOS No. 30650939 (PRECISION). Computational resources have been provided by the Consortium des Équipements de Calcul Intensif (CÉCI), funded by the F.R.S.-FNRS under Grant No. 2.5020.11 and by the Wallonia Region. CK and SR are grateful to the Région Languedoc-Roussillon (grant Chercheurs d'Avenir-2015, No. 005984) and the FEDER (Fonds Européen de Développement Régional) for financial support. CK acknowledges UMONS for a Ph.D. grant. The ITC equipment is part of the Integrated Screening Platform of Toulouse (PICT, IBiSA).

\section{SUPPLEMENTARY MATERIAL}

The Supplementary Material for this article can be found online at: https://www.frontiersin.org/articles/10.3389/fchem. 2019.00493/full\#supplementary-material

Grabowski, Z. R., Rotkiewicz, K., and Rettig, W. (2003). Structural changes accompanying intramolecular electron transfer: focus on twisted intramolecular charge-transfer states and structures. Chem. Rev. 103, 3899-4032. doi: 10.1021/cr9407451

Hänsel-Hertsch, R., Di Antonio, M., and Balasubramanian, S. (2017). DNA Gquadruplexes in the human genome: detection, functions and therapeutic potential. Nat. Rev. Mol. Cell Biol. 18, 279-284. doi: 10.1038/nrm.2017.3

Hanwell, M. D., Curtis, D. E., Lonie, D. C., Vandermeersch, T., Zurek, E., and Hutchison, G. R. (2012). Avogadro: an advanced semantic chemical editor, visualization, and analysis platform. J. Cheminform. 4:17. doi: 10.1186/1758-2946-4-17

Hong, Y., Xiong, H., Lam, J. W., Häußler, M., Liu, J., Yu, Y., et al. (2010). Fluorescent bioprobes: structural matching in the docking processes of aggregation-induced emission fluorogens on DNA surfaces. Chem. Eur. J. 16, 1232-1245. doi: 10.1002/chem.200900778

Huang, J., Yang, X., Wang, J., Zhong, C., Wang, L., Qin, J., et al. (2012). New tetraphenylethene-based efficient blue luminophors: aggregation induced emission and partially controllable emitting color. J. Mater. Chem. 22, 2478-2484. doi: 10.1039/C1JM14054J

Jaghoori, M. M., Bleijlevens, B., and Olabarriaga, S. D. (2016). 1001 ways to run AutoDock Vina for virtual screening. J. Comput. Aided Mol. Des. 30, 237-249. doi: $10.1007 /$ s10822-016-9900-9

Kayal, S., Roy, K., and Umapathy, S. (2018). Femtosecond coherent nuclear dynamics of excited tetraphenylethylene: ultrafast transient absorption and ultrafast Raman loss spectroscopic studies. J. Chem. Phys. 148:024301. doi: $10.1063 / 1.5008726$

Lam, E. Y. N., Beraldi, D., Tannahill, D., and Balasubramanian, S. (2013). Gquadruplex structures are stable and detectable in human genomic DNA. Nat. Commun. 4:1796. doi: 10.1038/ncomms2792

Maji, B., and Bhattacharya, S. (2014). Advances in the molecular design of potential anticancer agents via targeting of human telomeric DNA. Chem. Commun. 50, 6422-6438. doi: 10.1039/C4CC00611A

Mei, J., Hong, Y., Lam, J. W. Y., Qin, A., Tang, Y., and Tang, B. Z. (2014). Aggregation-induced emission: the whole is more brilliant than the parts. Adv. Mater. 26, 5429-5479. doi: 10.1002/adma.201401356

Monchaud, D., and Teulade-Fichou, M.-P. (2008). A hitchhiker's guide to Gquadruplex ligands. Org. Biomol. Chem. 6, 627-636. doi: 10.1039/B714772B

Neidle, S. (2017). Quadruplex nucleic acids as targets for anticancer therapeutics. Nat. Rev. Chem. 1:0041. doi: 10.1038/s41570-017-0041

Odabas, S., Tekin, E., Turksoy, F., and Tanyeli, C. (2013). Inexpensive and valuable: a series of new luminogenic molecules with the tetraphenylethene core having excellent aggregation induced emission properties. J. Mater. Chem. C 1:7081-7091. doi: 10.1039/c3tc31427h

Phan, A. T. (2010). Human telomeric G-quadruplex: structures of DNA and RNA sequences. FEBS J. 277, 1107-1117. doi: 10.1111/j.1742-4658.2009.07464.x 
Renciuk, D., Zhou, J., Beaurepaire, L., Guédin, A., Bourdoncle, A., and Mergny, J.L. (2012). A FRET-based screening assay for nucleic acid ligands. Methods 57, 122-128. doi: 10.1016/j.ymeth.2012.03.020

Rubio-Magnieto, J., Di Meo, F., Lo, M., Delcourt, C., Clément, S., Norman, P., et al. (2015). Binding modes of a core-extended metalloporphyrin to human telomeric DNA G-quadruplexes. Org. Biomol. Chem. 13, 2453-2463. doi: 10.1039/C4OB02097A

Salimimarand, M., La, D. D., Kobaisi, M. A., and Bhosale, S. V. (2017). Flowerlike superstructures of AIE-active tetraphenylethylene through solvophobic controlled self-assembly. Sci. Rep. 7:42898. doi: 10.1038/srep42898

Schultz, A., Laschat, S., Diele, S., and Nimtz, M. (2003). Tetraphenylethene-derived columnar liquid crystals and their oxidative photocyclization. Eur. J. Org. Chem. 2003, 2829-2839. doi: 10.1002/ejoc.200300118

Shigeta, M., Morita, M., and Konishi, G. (2012). Selective formation of twisted intramolecular charge transfer and excimer emissions on 2,7bis(4-Diethylaminophenyl)-fluorenone by choice of solvent. Molecules 17, 4452-4459. doi: 10.3390/molecules17044452

Sinha, N., Stegemann, L., Tan, T. T., Doltsinis, N. L., Strassert, C. A., and Hahn, F. E. (2017). Turn-on fluorescence in tetra-NHC ligands by rigidification through metal complexation: an alternative to aggregation-induced emission. Angew. Chem. Int. Ed. 56, 2785-2789. doi: 10.1002/anie.201610971

Trommel, J. S., and Marzilli, L. G. (2001). Synthesis and DNA binding of novel water-soluble cationic methylcobalt porphyrins. Inorg. Chem. 40, 4374-4383. doi: $10.1021 / \mathrm{ic} 010232 \mathrm{e}$

Trott, O., and Olson, A. J. (2009). AutoDock vina: improving the speed and accuracy of docking with a new scoring function, efficient optimization, and multithreading. J. Comput. Chem. 31, 455-461. doi: 10.1002/jcc.21334

Tucker, W. O., Shum, K. T., and Tanner, J. A. (2012). G-quadruplex DNA aptamers and their ligands: structure, function and application. Curr. Pharm. Des. 18, 2014-2026. doi: 10.2174/138161212799958477

Wang, J., Wolf, R. M., Caldwell, J. W., Kollman, P. A., and Case, D. A. (2004). Development and testing of a general amber force field. J. Comput. Chem. 25, 1157-1174. doi: $10.1002 /$ jcc.20035
Wang, Y., and Patel, D. J. (1993). Solution structure of the human telomeric repeat d[AG3(T2AG3)3] G-tetraplex. Structure 1, 263-282. doi: 10.1016/0969-2126(93)90015-9

Wu, Y., and Brosh, R. M. (2010). G-quadruplex nucleic acids and human disease. FEBS J. 277, 3470-3488. doi: 10.1111/j.1742-4658.2010.07760.x

Yang, Z., Qin, W., Leung, N. L. C., Arseneault, M., Lam, J. W. Y., Liang, G., et al. (2016). A mechanistic study of AIE processes of TPE luminogens: intramolecular rotation vs. configurational isomerization. J. Mater. Chem. C. 4, 99-107. doi: 10.1039/C5TC02924D

Zhang, H., Nie, Y., Miao, J., Zhang, D., Li, Y., Liu, G., et al. (2019). Fluorination of the tetraphenylethene core: synthesis, aggregation-induced emission, reversible mechanofluorochromism and thermofluorochromism of fluorinated tetraphenylethene derivatives. J. Mater. Chem. C 7, 3306-3314. doi: 10.1039/C9TC00511K

Zhang, Q., Liu, Y.-C., Kong, D.-M., and Guo, D.-S. (2015). Tetraphenylethene derivatives with different numbers of positively charged side arms have different multimeric G-quadruplex recognition specificity. Chem. Eur. J. 21, 13253-13260. doi: 10.1002/chem.201501847

Zhao, C., Wu, L., Ren, J., Xu, Y., and Qu, X. (2013). Targeting human telomeric higher-order DNA: dimeric G-quadruplex units serve as preferred binding site. J. Am. Chem. Soc. 135, 18786-18789. doi: 10.1021/ja410723r

Conflict of Interest Statement: The authors declare that the research was conducted in the absence of any commercial or financial relationships that could be construed as a potential conflict of interest.

Copyright (c) 2019 Kotras, Fossépré, Roger, Gervais, Richeter, Gerbier, Ulrich, Surin and Clément. This is an open-access article distributed under the terms of the Creative Commons Attribution License (CC BY). The use, distribution or reproduction in other forums is permitted, provided the original author(s) and the copyright owner(s) are credited and that the original publication in this journal is cited, in accordance with accepted academic practice. No use, distribution or reproduction is permitted which does not comply with these terms. 